\section{RevistadePolítica Económica y Desarrollo Sostenible}

Centro Internacional de Política Económica para el Desarrollo Sostenible
Revista de Política Económica y Desarrollo Sostenible

EISSN: 2215-4167 • Vol. 1 (1) • Julio-Diciembre, 2015: 1-17

DOI: http://dx.doi.org/10.15359/peds.1-1.3

URL: http://www.revistas.una.ac.cr/politicaeconomica

Revista electrónica semestral publicada por el Centro Internacional de Política Económica para el Desarrollo Sostenible

Universidad Nacional, Lagunilla, Heredia Apartado 2393-3000

\title{
Papel y Evolución de las Instituciones en la Dinámica Económica Salvadoreña 1979-2008: Una mirada evolucionista e histórica
}

\author{
Role and evolution of institutions in the Salvadoran economic dynamics 1979- \\ 2008: An evolutionary and historical look
}

\author{
Karla Guzmán López $z^{1}$ Julián Salinas Ventura²
}

Fecha de recepción: 24.02.2015 Fecha de aceptación: 23.06.2015 Fecha de publicación:04.11.2015

\begin{abstract}
Resumen
Este trabajo analiza las instituciones en relación a los cambios económicos más significativos en El Salvador. La investigación engloba el período 1979 - 2008 porque en este ocurren cambios económicos estructurales tales como la crisis y establecimiento de un nuevo modelo económico, lo cual lo vuelve idóneo para analizar desde una perspectiva histórica y evolucionista los sectores favorecidos y perjudicados, el tipo de dinámica económica influenciada por las políticas implementadas. El objetivo es proporcionar información relevante para dar preponderancia al papel de las instituciones en la historia socioeconómica, muchas veces omitidas en los análisis económicos, sin embargo la importancia de las instituciones en el espectro económico salvadoreño fue determinante alrededor del período de estudio.
\end{abstract}

Palabras Clave: Instituciones, modelo económico, estado, neoliberalismo, cambio histórico

\begin{abstract}
In this paper we will analyze the most significant historical changes in economic and institutional areas which took place in El Salvador, showing the relationship causal between them. Research was done around years 1980 - 2008, because it was an ideal period to study from a historical and evolutionist perspective, the changes happened in El Salvador, advantaged and disadvantaged sectors and type of economic dynamics influenced by the policies implemented. This with objective to provide relevant information to give prominence to the role of institutions in the socioeconomic history, often omitted from economic analysis, however the importance of institutions to economic spectrum Salvadorian were determinants during period of study.
\end{abstract}

Keywords: Institutions/ agro export model /state /neoliberalism / historical change

1 Magister Scientiae en Política Económica por el Centro Internacional en Política Económica (Cinpe) - UNA. Catedrática de la Facultad de Ciencias Económicas de la Universidad de El Salvador. Miembro de la red de Ex becarios del DAAD para la investigación (CADAN: R). Correo electrónico: karla.guzman@ues.edu.sv

2 Magister Scientiae en Política Económica, Licenciado en Economía y asesor económico de la Comisión de Hacienda del FMLN en la Asamblea Legislativa de El Salvador. Miembro de la Red Centroamericana de Ex becarios del DAAD para la Investigación (CADAN: R). Correo electrónico: julianventura7@gmail.com 


\section{Introducción}

La historia salvadoreña ha seguido etapas muy significativas desde la crisis del modelo agroexportador, las reformas de ajuste estructural y en la actualidad una economía insertada en una dinámica globalizada. Todas estas etapas implicaron modificaciones respecto a la intervención o no del Estado en la economía, las nuevas reglas del juego, los nuevos agentes en los mercados, y los nuevos mecanismos de determinación.

Ante estos hechos, el estudio del papel y evolución de las Instituciones en la dinámica histórica de la economía salvadoreña es de relevancia porque permite analizar el tipo de vinculación que se dio en El Salvador entre ambos elementos en el período 1979-2008. Además permite conocer las razones de esos cambios y la evolución de las instituciones marcadas en muchos casos por los intereses de determinados grupos económicos.

El artículo inicia con el abordaje teórico (sección 1) en el cual, a partir de un enfoque neoinstitucionalista, se sienta los referentes para entender el cambio institucional; posterior a ello, se explica el método empleado. Seguidamente, y por etapas históricas (sección 3), se aborda la evolución de las instituciones en la dinámica económica de El Salvador, para finalizar en el acápite 5 con las conclusiones del análisis.

\section{Análisis institucional desde una perspectiva histórica-evolucionista}

Las instituciones son definidas por North (1993) como las reglas del juego en una sociedad; más formalmente son las limitaciones ideadas por el hombre que dan forma a la interacción humana. Por consiguiente, estructuran incentivos en el intercambio humano, sea político, social o económico.

De ahí que el análisis neoinstitucional va más allá que el enfoque neoclásico basado fundamentalmente en los mercados, y muchos supuestos restrictivos que podrían no coincidir con la realidad, como el individualismos metodológico, intercambio voluntario y la eficiencia (Caballero, 2004). Mientras que los institucionalistas estudian los aspectos económicos en el nivel micro tales como: los costos de realizar transacciones en los mercados o el problema de los derechos de propiedad.

Villareal (2009) considera que en el enfoque institucionalista se demanda la inclusión de aspectos que se marginan en el enfoque neoclásico, y que son fundamentales para el buen funcionamiento de los mercados, como: el marco jurídico, las estructuras de poder, el acceso a la información, la formación de los individuos (cultura y valores) y hasta las características del sistema político, alrededor de lo que se conoce como instituciones o reglas del juego y las organizaciones o actores.

La definición de instituciones considera a los mercados como una institución con un marco jurídico tanto formal como informal que determina el carácter de las reglas del juego y de los jugadores. Es prudente concebir, entonces, que existe un vínculo entre los mercados y la historia económica de un país, y es a partir del enfoque neoinstitucional que se pueden integrar 
los dos factores más importantes para el funcionamiento eficiente de los mercados: la estructura institucional y organizativa de la economía.

Según Ayala (1999), uno de los aspectos que se analizan de la economía y el mercado se enfoca en las estructuras de poder tanto desde la perspectiva de la organización y el control de sistema economía y proceso jurídico. También se enfocan en los problemas de asignación de recursos, y por ultimo supone que los agentes económicos actúan colectivamente a través del mercado y del proceso político y jurídico para encontrar soluciones a problemas de asignación de recursos y distribución del ingreso.

Las teorías sobre las instituciones, según Ayala (1999), se agrupan en dos tradiciones intelectuales. Las teorías del primer grupo enfatizan los beneficios colectivos que se desprenden de su existencia, mientras que las segundas, enfatizan conflictos sociales y distributivos que generan, porque se argumenta que las instituciones no benefician a todos los agentes por igual. Los cuatro enfoques para estudiarlas son: el análisis neoclásico, contractualista, el evolucionista e histórico.

En este caso en particular, se realiza un análisis que recurre a los planteamientos evolucionista e histórico. En relación a estos enfoques, Ayala (1999) sostiene que la economía evolucionista supone que las instituciones se seleccionan y mantienen porque la competencia en el mercado y entre las mismas instituciones conducirá a la sobrevivencia de las instituciones más eficientes. Mientras tanto las teorías históricas explican la evolución de las instituciones como el resultado de los cambios en la historia. De acuerdo con Ayala:

El enfoque histórico muestra la evolución de las instituciones en el largo plazo, es decir, el impacto de las instituciones en el tránsito de sociedades poco complejas a muy complejas, de reglas informales y consuetudinarias a reglas escritas y formalmente establecidas en códigos legales. (1999; pág. 60).

Las instituciones formales son las reglas escritas en las leyes y reglamentos, y son construcciones expresamente creadas por los individuos para encarar problemas específicos de coordinación económica, social y política. Las instituciones informales, son las reglas no escritas, que se van acumulando a lo largo del tiempo, y quedan registradas en los usos y costumbres" (1999; pág. 66).

Por su parte North (1993), refiriéndose a la historia, la considera importante no sólo porque se puede aprender del pasado, sino también porque el presente y el futuro están conectados al pasado por obra de la continuidad de las instituciones de una sociedad. La estructura económica de las instituciones, tal cual se definió anteriormente, cambia según una enorme variedad de formas, no obstante, caen en tipos generalizados que son congruentes con el modelo de costo de cambio de las negociaciones. 


\section{Método}

La investigación toma como referencia la visión neoinstitucional enriquecida con los enfoques histórico y evolucionista. Esto debido a que las instituciones están moldeadas por factores históricos que limitan las opciones de los agentes (Ayala, 1999). En lo que a la categoría "cambios institucionales" refiere, estos se centran en las instituciones formales, dejando el componente informal como un carácter complementario, por la dificultad de hacer un análisis histórico que las considere lo que no implica, pasar por alto algunos aspectos determinantes en dicho ámbito.

Se realiza un análisis empírico sobre el vínculo cambios económicos y cambios institucionales. Para ello se establece un período de análisis de veintinueve años subdividido en tres momentos históricos representativos para la historia económica reciente de El Salvador. El primer período 1979-1989 se selecciona porque representa el derrumbe del modelo agroexportador a finales de los años ochenta en conjunto del inicio de la guerra civil en el país.

El segundo momento histórico de la década los noventa (1990-1999) representa la instauración de un modelo económico basado en la dinámica importadora - financiera que vino acompañado de los programas de ajuste estructural y de estabilización económica no solo en El Salvador sino en toda la región centroamericana. El tercer subperíodo (2000-2008) se elige porque representa la continuidad de medidas de corte neoliberal y los momentos previos a la crisis económica mundial y sus consecuencias en la economía salvadoreña.

La metodología es del tipo cualitativa, donde se recurre a la experiencia en investigación sobre la historia económica de El Salvador de un grupo de expertos a través del instrumento de la entrevista. Esto permite contextualizar los hechos económicos y su relación con los cambios institucionales.

Para el análisis instituciones-economía se construye una línea de tiempo (ver anexos) que ilustra las transformaciones en estos ámbitos. Esta permite visualizar y entablar de mejor manera la relación que existe entre los cambios registrados en el período.

\section{Evolución de las instituciones y su influencia en la Economía Salvadoreña.}

\subsection{Agotamiento del modelo agroexportador (1979-1989)}

Los años ochenta se caracterizaron por ser un periodo de guerra civil, con cambios económicos fundamentales, un modelo agroexportador que se agotaba y cambios institucionales que marcaron la década. En 1979 se dio el golpe de estado lo cual marcó el quiebre de la dictadura militar mantenida por casi cincuenta años, se instauró la junta revolucionaria de gobierno que cuatro años más tarde, en 1983, haría modificaciones a la principal institución formal del país, la Constitución de la Republica, derogando la de 1962 (Equipo Maíz, 2005; Peñate, 1997). 
Los impactos en las instituciones posteriores a un golpe de estado, se observan en el cambio drástico de las reglas en la esfera tanto informal, como formal. En el nivel informal los cambios se dan a partir de los intereses que se superponen en las organizaciones públicas, los impactos en la esfera social, en el mercado y en los agentes que participan del mismo. Mientras que en el nivel formal las secuelas del golpe estatal se manifiestan en los cambios al interior de las organizaciones públicas, las leyes y el ejercicio de las políticas públicas que impactan sensiblemente en el aparato productivo nacional.

Pelupessy (1995) hace una reflexión muy pertinente en lo concerniente a los cambios institucionales, loscuales no siempretienen unafundamentacióneconómica comoeselcasoaducido, sinoqueteníaun trasfondopolíticodesdedondesebuscaresolverunacrisispolíticaendesarrollo. Las decisionesimpactan significativamenteenlasinstituciones relacionadasconelescenarioeconómico , aunque su propósito era fundamentalmente político.

A partir de 1980 se hicieron algunas reformas como la nacionalización de la banca, la reforma agraria y la nacionalización del comercio exterior del café y azúcar, donde se crearon organismos estatales como Instituto Nacional del Café (Incafe) e Instituto Nacional del Azúcar (Inazucar) quienes administrarían las exportaciones de café y azúcar (Pelupessy, 1995).

En 1984 llega al poder el Partido Demócrata Cristiano (PDC) que no coincidía con los intereses de los grupos de poder hegemónicos -sobre todo en la política económica- $y$ aplicó un conjunto de reformas en el país que iban orientadas a fortalecer el mercado interno, desconcentrar la propiedad de la tierra (crear cooperativas) y darle una mayor participación al Estado en la actividad económica.

Esto marcaría cambios institucionales tanto el surgimiento de nuevas organizaciones formales, como en las leyes y los sectores beneficiados por dichas políticas en detrimento de algunos grupos que hasta el momento se beneficiaban de las reglas establecidas hasta esa fecha (Equipo Maíz, 2005)

Hasta el año 1989, cuando se inició el programa de ajuste estructural, la economía salvadoreña tenía un fuerte componente de intervención estatal y de regulación de mercados por parte de entidades públicas. La propiedad estatal era muy fuerte e incluía la banca y las asociaciones de ahorros y préstamos que fueron nacionalizadas en 1980, el comercio exterior del café y del azúcar, también nacionalizados, el monopolio de la telefonía y de la generación y distribución eléctrica, el Instituto Regulador de Abastecimientos (Ira), los ingenios azucareros y muchos otros negocios comerciales, y de servicios" (C. Villalona, comunicación personal, 12 de agosto de 2010).

Villalona (comunicación personal, 12 de agosto de 2010), asegura que además de la propiedad, el Estado también intervenía en el funcionamiento de los mercados y sobre todo en los precios de bienes y servicios, en algunas tarifas (como la de transporte y electricidad) y en el control de las divisas. El Estado fijaba la tasa de interés a través del Banco Central 
de Reserva (BCR), el tipo de cambio y los precios de 230 productos y servicios de la canasta básica. También protegía a la industria y el agro local mediante elevados aranceles, de hasta $230 \%$ sobre el valor de importación, la institucionalidad formal para regular los mercados estaba influenciada por la intervención estatal.

El conjunto de reformas, afectó y debilitó el modelo agroexportador, los grupos de poder económico ya no podían acceder directamente a los ingresos por exportaciones que se encontraban en esos rubros, es decir, del azúcar y café; a la vez que se les limitaba el acceso al crédito con la banca nacionalizada.

En la estructura productiva salvadoreña el sector agropecuario aun tenía mucha importancia para la actividad económica basada en la producción y exportación tradicional. Según el BCR, en 1985 las exportaciones tradicionales constituían el 72.8\% del total, el 27.2\% restante eran exportaciones no tradicionales y maquila. Cinco años más tarde, las exportaciones tradicionales constituían el $44.7 \%$ de las totales (BCR,1990).

En cuanto a los actores, durante la década de los ochenta existían grupos campesinos que actuaban bajo formas no salariales sino más bien de subsistencia, así como también se había fortalecido la producción cooperativa -después de la reforma agraria-. Las nuevas formas de organización eran cooperativas muy vinculadas a los cambios económicos e institucionales, pero por otro, la fuerza de trabajo asalariada ubicada en el campo, se estaba volviendo escasa debido a las migraciones tanto a la zona urbana y hacia el extranjero, tal y como lo cita Ruiz:

En este período hubieron dos tipos de cambios institucionales, los provenientes de la empresa privada y los que se produjeron en las empresas de gobierno. Las instituciones de la empresa privada comenzaron a impulsar el modelo neoliberal desde 1979 en este mismo año comienza la organización política de la empresa privada, primero con el agrupamiento de organizaciones de agricultores interesados en oponerse a la reforma agraria, luego se incorporaron otras organizaciones de la empresa privada para fortalecer a la Asociación Nacional de la Empresa Privada (Anep) fundada en 1966, paralelamente se dio la organización política de la empresa privada en el Partido Alianza Republicana Nacional (ARENA).

En 1983/84 se creó la Fundación Salvadoreña para el Desarrollo (Fusades) financiada por cooperación internacional, especialmente de Estados Unidos, que proponía y difundía entre la empresa privada y la ciudadanía en general las políticas económicas y sociales pertinentes para aplicar un modelo de desarrollo neoliberal" (S. Ruiz, comunicación personal, 29 de julio de 2010).

Además de esta reacción de parte de los agentes perdedores con los cambios institucionales también los cafetaleros se vieron afectados por las crisis del café a escala mundial a finales de 
los ochenta, y la subsecuente crisis del modelo económico salvadoreño. La presión de la deuda cafetalera también atrapó a los pequeños productores, muchos de ellos perdieron tierras para pagar las deudas a final de la década (Pelupessy, 1995). Fue en el año1989 que se creó El Consejo Salvadoreño del Café (CSC), como el ente rector de la caficultura en El Salvador previo a la abolición del Instituto Nacional del Café (Incafe).

Acevedo (comunicación personal, 16 de agosto de 2010) hace su valoración sobre los grupos de agentes perdedores y ganadores, con los cambios institucionales y considera que en este periodo, la Fuerza Armada fue un sector bastante beneficiado. Por otra parte, el conflicto bélico afectó a muchos sectores, a diversos niveles y de distintas maneras, refiriéndose a la población en general. Mientras que la estatización de la economía claramente afectó los intereses de grupos económicos poderosos (agroexportadores, banqueros, etc.). Por lo tanto, los agentes perdedores y ganadores de los cambios en las instituciones, buscaron sus alternativas para crear sus propias instituciones.

Al cierre de la década (del 80), la situación política del país era delicada y la llegada al poder de ARENA que representaba los intereses de los grupos de poder económico y la ofensiva guerrillera marcarían un nuevo giro de la economía e institucionalidad en el país durante la siguiente década.

\subsection{Ajuste estructural y reformas Neoliberales (1990-1999)}

Este periodo, está marcado por fuertes cambios económicos, a partir de los programas de ajuste estructural y de estabilización económica, donde el papel de la política económica y de las instituciones sería fundamental. El gobierno inició con el "Plan de Desarrollo Económico Social 1989-1994", orientado al programa de estabilización de corto plazo con aportes del Fondo Monetario Internacional (FMI), y por otra parte, un programa de ajuste estructural del Banco Mundial (BM) que según el gobierno buscaba crear una economía estable y competitiva que estimulara el crecimiento, así como también buscaba transformar la estructura productiva (Hutt, Montesinos y Ochoa, 2000).

Dos hechos destacables para comprender los cambios institucionales son los préstamos otorgados por el Banco Mundial para el ajuste estructural . Estos condicionaban la aplicación de medidas económicas, reformas jurídicas y de las organizaciones públicas en varias áreas tendientes a instaurar un modelo desde el pensamiento neoliberal, pero sobretodo orientados a: la privatización de empresas estatales, liberalización económica y reforma tributaria (Hutt et al, 2000).

Las regulaciones en los mercados cambiaron enormemente sobretodo en los de bienes exportables. Se eliminó el control del Estado en el comercio exterior con el traspaso de los bienes del Inazucar y del Incafe a los sectores privados. Desde entonces el mercado de café se organiza de manera que los mismos cafetaleros venden el producto en el exterior sin ninguna 
intervención estatal más que para trámites y en el caso de importaciones, se privatizaron las importaciones de petróleo (Equipo Maíz, 2003).

El Estado perdió propiedades como resultado de la privatización y dejó de regular los mercados mediante la liberalización de los precios de bienes y servicios, del cierre el Ira y la supresión de los precios de garantía a la pequeña producción campesina, la liberalización de la tasa de interés y del tipo de cambio y la eliminación de algunos subsidios. También redujo aranceles. Los organismos que antes fijaban precios, como el Ministerio de Economía y el BCR, redujeron significativamente su poder de regulación." (C. Villalona, comunicación personal, 12 de agosto de 2010).

Por otro lado, se creó un marco institucional para fortalecer los sectores del nuevo modelo. Se reformó el sistema financiero con la "Ley de Privatización de los Bancos Comerciales y de las Asociaciones de Ahorro y Préstamo” en 1990, así como también se aprobó la nueva Ley Orgánica del BCR que le impedía actuar como prestamista de última instancia del gobierno, además no podía controlar las tasas de interés (Guzmán y Salinas, 2008).

Las transformaciones fueron muchas en materia cambiaria, se fijó el tipo de cambio pues se pasó de flotación sucia en 1990 hasta 1993, que se fijó el tipo de cambio a $\$ 8.75$ por un dólar, medida que el gobierno lanzaba para eliminar el riesgo cambiario en beneficio de aquellos que tenían deuda en dólares en el mercado internacional (Segovia, 2002), en sí una medida que se fortalecía en la institucionalidad para reducir costos de transacción de los agentes.

En el tema de impuestos y subsidios, el Estado salvadoreño hizo varias reformas como la eliminación del impuesto al patrimonio que gravaba la propiedad, y se creó el Impuesto al Valor Agregado (IVA), inicialmente con una tasa del 10\%, que en 1995 se aumentó hasta 13\% (Hutt et al, 2000). A partir de diciembre de 1996, las importaciones de bienes de capital y materias primas estarían exentas de impuestos mientras que el arancel para los bienes intermedios alcanzaría un rango entre 5\% y $10 \%$ en julio de 1999.

Segovia (2002) destaca que mientras se implementaban acciones tendientes a liberalizar el comercio exterior, también se ejecutaban medidas de tipo ofertista para atraer inversión extranjera. Entre ellas se mencionan la creación de incentivos fiscales para los inversionistas con leyes de zonas francas y los incentivos a las exportaciones de devolverles el 6\% del valor FOB de estas.

Ante las repercusiones económicas y sociales de la aplicación de la primera fase del modelo económico, el gobierno avanzó con rapidez hacia las otras dos fases en que se pretendía compensar esas repercusiones sobre las grandes mayorías de la población. La segunda fase en 1996, incorporó la privatización y fomento del sector privado en la prestación de servicios públicos que incluyó la privatización de las telecomunicaciones, las distribuidoras de energía eléctrica y la reforma en el sistema de pensiones (Hutt et al, 2000). 
Estos cambios tenían a la base, un modelo basado en la iniciativa privada, apertura comercial y transformación de la estructura productiva hacia los sectores no tradicionales (C. Villalona, comunicación personal, 12 de agosto de 2010).

El motivo de estos cambios se debió a que los sectores de poder querían convertir a El Salvador en el sexto dragón del pacifico, con una industria en donde el $90 \%$ de las exportaciones fueran industriales. La mayor parte del crédito se orientaría a la industria para la exportación, que a su vez sería la primera fuente de empleo y de ingresos fiscales, con los dólares generados se compraría en el exterior la maquinaria para la industria e insumos para la agricultura -esta era la idea del modelo de exportación no tradicional- (C. Villalona, comunicación personal, 12 de agosto de 2010).

Sin embargo, con el tiempo la idea de modelo se modificó. Un factor importante fueron las migraciones de salvadoreños hacia Estados Unidos que provocaron la entrada de divisas en concepto de remesas familiares, a tal grado que la base exportadora quedó suplantada como principal fuente de divisas, por las remesas familiares (se fortalece una institución informal que sostiene los ingresos de miles de salvadoreños).

Acevedo (2003, pág.8) al respecto de la importancia de las remesas sostiene que “

Si bien los flujos migratorios de salvadoreños hacia el exterior fueron considerables desde la década de los setenta, no es sino hasta los noventa que las remesas alcanzan verdadera relevancia macroeconómica y social. Estas pasaron de $\$ 5$ millones en 1970, a \$327 millones en 1989, equivalente a 6.6\% del PIB. Durante los noventa, los flujos de remesas se han mantenido en promedio en alrededor de $\$ 1,100$ millones por año, representando $13.3 \%$ del PIB en 2000"

A partir de 1989, uno de los grandes sectores ganadores del proceso de reformas económicas y legales fue la banca (al recibir un precio muy bajo un sistema financiero saneado con recursos del Estado). En general, el sector servicios ha sido uno de los más beneficiados con el modelo económico imperante desde comienzos de los 1990 (C. Acevedo, comunicación personal, 16 de agosto de 2010).

Los perdedores de todos estos cambios fueron los agricultores tradicionales, la industria orientada a la producción nacional, y los trabajadores, pues bajo el lineamiento de los ajustes, las instituciones en materia laboral se modificaron.

Bajo la justificación de reducir el gasto público, se creó la "Ley de retiro obligatorio" para reducir el gasto corriente, lo cual generó desempleo por el sector público. También se dio la flexibilización del mercado laboral, donde las empresas comenzaron a practicar diferentes medidas que iban en detrimento de la calidad laboral de los trabajadores: la contratación temporal para evitar la indemnización de los trabajadores, congelamiento en la revisión de salarios mínimos, prohibición para la organización sindical y contratación por aprendizaje, medidas que muchas veces crean condiciones de subempleo (Guzmán y Salinas, 2008). 
"El cambio institucional en este periodo fue el determinante principal de constituir una economía de mercado consistente con el esquema neoliberal patrocinado por el Consenso de Washington en aquel momento." (C. Acevedo, comunicación personal, 16 de agosto de 2010).

\subsection{Continuidad de políticas neoliberales y antesala a la crisis financiera internacional (2000-2008)}

En los albores de este período se desata una continuidad de muchas medidas enmarcadas en la dinámica del ajuste estructural y la estabilización económica, donde ninguna de estas puede ser completamente explicada desde una dimensión estrictamente teórica, aunque su fundamentación expresa haya estado cargada hacia el paradigma neoliberal. Más bien, cada una tiene una justificación desde la perspectiva de los intereses de los grupos ganadores, para estimular una dinámica institucional a imagen y semejanza de los objetivos implícitos y no necesariamente expresos (Guzmán y Salinas, 2008).

En este contexto se impulsan varias políticas públicas que impactan en lo institucional: la dolarización y los tratados de libre comercio con diversos países donde destacan los negociados con Estados Unidos y México.

La dolarización fue una medida polémica, antidemocrática y de gran dimensión adoptada para el año 2001, aunque ciertamente se venía proponiendo desde un lustro atrás. Esta política no se implementó hasta el 2001 por varias razones: una fue que se quería esperar hasta tener una acumulación de reservas que ascendiera a un nivel significativo, la segunda fue las presiones económicas de algunas instancias como, COEXPORT, FUSADES y la ANEP que demandaban una devaluación del tipo de cambio para la búsqueda de competitividad (Villalona, 2002).

La propuesta de devaluación que algunos sectores sostenían, era además una medida contracíclica ante la reciente crisis de producción evidenciada en el año 2000 y esto mismo era compatible con las pretensiones del ajuste estructural que propenden al desarrollo del sector exportador no tradicional.

La otra razón por la cual se impulsa la dolarización de manera apresurada es por la posible llegada de un gobierno de izquierda al gobierno (FMLN ), donde una economía dolarizada evitaría el riesgo de devaluación y por el otro mantendría el control de liquidez en manos privadas (Villalona, 2002).

Ahora bien, la devaluación no es compatible con la dinámica económica predominante, centrada hacia actividades terciaristas, considerando que una devaluación si bien es cierto abarata las exportaciones, también encarece las importaciones. Esto demandó una implementación rápida e inconsulta de la dolarización priorizando los intereses de los sectores importadores y financieros , por sobre los exportadores. Esta medida socava por completo las posibilidades de construir un modelo exportador al estilo Taiwanés. 
Los TLC's por otra parte constituyen un sustento jurídico para la aplicación de las políticas neoliberales en El Salvador, permitiendo el accionar libre del capital extranjero, profundizando la liberalización arancelaria y generando mecanismos jurídicos supranacionales (Moreno, 2004).

El trasfondo de estas medidas también es compatible con la continuidad y profundización de un modelo financiero y de comercio importador, esto significa que con estas reformas los costos de transacción se reducen a favor de los importadores y banqueros a quienes les es más factible emprender sus negocios, generándoles mayor ventaja no solo política, sino económica.

Aunque las reformas eran de naturaleza económica, no podrían haberse implementado sin la creación de instituciones funcionales a los objetivos económicos implícitos en cada una de estas. En tal sentido la dolarización y los tratados de libre comercio son macromedidas que implican transformaciones institucionales cuya vinculación entre los objetivos económicos y el diseño de las políticas se hace mediante "las instituciones".

Lo anterior implica que cada una de las medidas tiene relevancia económica e impacto en los agentes y en el intercambio, gracias a las transformaciones institucionales implícitas que afectan expectativas, costos de transacción e inclusive contratos. Así la dolarización transforma organizaciones como las funciones del BCR, afecta la moneda que puede considerarse una institución, afecta leyes, afecta las organizaciones económicas dando mayor poder a determinados sectores económicos como los banqueros e importadores.

Esta misma lectura puede hacerse de los TLC's donde su ratificación lleva implícitas la vigencia de normas nacionales y supranacionales, abarata costos de transacción y favorece condiciones de poder para las organizaciones económicas exportadoras e importadoras del mercado Estadounidense.

Lo contrario puede decirse de los pequeños sectores informales que comercian productos restringidos por la propiedad intelectual o los sectores agropecuarios e industriales que destinan su producción al mercado interno y son amenazados por la competencia extranjera, o aquellos sectores exportadores centroamericanos donde las importaciones estadounidenses son una amenaza para la cuota de exportación dentro del mercado común centroamericano

Acevedo (comunicación personal, 16 de agosto de 2010) citando a Eduardo Engel sostiene que:

"En El Salvador las instituciones y políticas públicas han favorecido más los intereses de grupos privilegiados que el desarrollo de una verdadera economía competitiva de mercado (las políticas públicas han sido más "pro business" que "pro-market)".

Otras medidas que han llamado la atención, son algunas leyes que favorecen los intentos de dinamizar el mercado interno así como reformas fiscales que dilucidan la problemática latente en la recaudación fiscal, atribuido a los altos niveles de evasión y elusión fiscal, así como a la regresividad en la estructura impositiva (Hutt et al, 2000). 
Esto demanda particular atención hacia los intentos de reforma tributaria que han estado cargadas de conflictos buscando mantener el esquema regresivo que limita la capacidad para fortalecer una política fiscal proactiva y eficaz, que es en sí una de las limitadas herramientas del estado para ejercer política fiscal. "El Estado no tiene las propiedades que tenía antes e interviene menos en los asuntos económicos porque se liberalizó la mayor parte de la economía. Además, con la reforma tributaria el Estado ha tenido más problemas financieros, porque recauda más del pueblo, que tiene poco dinero, y recauda menos a costa de los grandes empresarios, que son los que tienen más dinero" (C. Villalona, comunicación personal, 12 de agosto de 2010).

En torno a esta dinámica socio institucional se han configurado ciertos factores que es necesario vislumbrar. La desigualdad ha aumentado si se considera que actualmente el $62 \%$ del PIB corresponde a ganancias mientras que en 1970 esta participación representaba el 50\% del PIB (C. Villalona, comunicación personal, 12 de agosto de 2010).

Por otra parte la dinámica importadora y financiera ha tenido tres implicaciones; primero un déficit comercial creciente -deteriorando las cuentas del sector externo- lo cual ha sido sustentable gracias a la remesas como generadoras de divisas, el déficit comercial (a precios constantes) fue en 1990 de \$-610 millones y en el 2007 fue de \$-2380 millones lo que refleja la creciente evolución de las importaciones (BCR, 1990 y 2007).

La segunda implicación ha sido una dinámica exacerbadamente consumista, de manera que para el 2007 el consumo supera con creces la producción (BCR, 1990 y 2007), representando el 106\% del PIB. Y finalmente un significativo efecto sobre la producción nacional caracterizada por un estancamiento de la industria y un deterioro del sector agropecuario.

La IED que ha llegado a El Salvador se ha ubicado en los sectores más rentables del aparato productivo nacional caracterizándose por ubicarse en aquellas actividades con mayor rentabilidad. Las más recientes, se han ubicado en el sector bancario de manera que para el 2007 era completamente transnacionalizado y los TLC's sin duda son un sustento institucional determinante.

Valga destacar que el tipo de IED ha estado articulada alrededor del traslado de unos dueños a otros -sobre todo en el sector financiero-, no ha generado nuevas fuentes de empleo ni tampoco, transferencias de tecnología significativas. Para el año 2007, el sector financiero percibió el 37\% de la IED del periodo (BCR, 1990 y 2007).

Finalmente la emigración asciende aproximadamente a 270,000 personas al año (C. Villalona, comunicación personal, 12 de agosto de 2010), de manera que la remesas son un sostén eminentemente estratégico para la economía y a su vez se ha configurado un círculo de exclusión. Mediante las políticas de corte neoliberal, se promueve la emigración que posteriormente se traduce en mayores remesas sus familiares.

Las remesas en 1989 fueron del 6.6\% del PIB (Acevedo, 2003); mientras que en el año 2007 fue del 16\% del PIB (Acevedo, 2003; C. Villalona, comunicación personal, 12 de agosto de 2010). 


\section{Conclusiones}

La dimensión histórica - evolucionista característica de esta investigación pone en evidencia el surgimiento, transformación y desaparición de instituciones cuya influencia en los mercados y en el aparto productivo nacional desempeña una preponderancia ineludible.

Las instituciones vigentes fueron en gran medida influenciadas mediante los intereses de los grupos ganadores. Es muy aleccionador observar que cada política pública ha tenido un papel influyente en los mercados, asumiendo el vínculo entre la implementación de las políticas y las instituciones formales e informales.

En los años 80 se dieron cambios institucionales relevantes para la transformación del modelo económico, sin embargo en este período se sentaron las bases para la finalización y surgimiento de un nuevo modelo económico, años en los que se desató una activa política contrainsurgente, una participación significativa del Estado en la economía y un periodo atípico en materia social, con un conflicto bélico atenuante en el entorno socioeconómico.

Los años 90 marcaron la finalización de un modelo agroexportador y el surgimiento de una dinámica importadora - financiera con una fuerte dependencia de las remesas para la generación de divisas, un desarrollo de los sectores comerciales pese a que en un inició se concibió un ajuste estructural orientado hacia la dinamización de las exportaciones no tradicionales.

Los resultados de este modelo han sido un deterioro del mercado interno y un fortalecimiento de un esquema financiero e importador que ha generado un elevado consumismo, desequilibrios en el sector externo, dependencia de las remesas, un modelo generador de desigualdad y exclusión y una creciente informalización de la actividad económica fruto de las búsquedas de alternativas -derivado de los efectos en la economía familiar-.

El modelo vigente ha sido el reflejo de cambios institucionales, algunos con características teleológicas, otros con un factor histórico aleatorio pero que independientemente de su fundamento ha influido sensiblemente en la actividad económica. Esto es trascendental porque permite ser concluyentes en que el funcionamiento de una dinámica económica específica, supone una estrategia institucional que propenda a la resolución de las principales deficiencias socioeconómicas, donde las instituciones desempeñan un papel relevante para tal propósito.

Queda por profundizar la evolución de las instituciones informales, actualizar el análisis en el marco del gobierno del FMLN (dicho partido político toma posesión en el año 2009) que ha impulsado cambios en el diseño de las políticas gubernamentales, las leyes y en el accionar de las organizaciones públicas que dan la pauta para estimular la evolución histórica de las instituciones salvadoreñas y su impacto en el sistema económico. 


\section{Referencias}

Acevedo, C. (2003). La Experiencia de Crecimiento Económico en El Salvador. El Salvador. Serie de Estudios Económicos y Sectorial, BID. Recuperado de: http://idbdocs.iadb.org/wsdocs/ getdocument.aspx? .docnum $=230980$

Ayala, J. (1999). Instituciones y Economía. México. Fondo de Cultura Económica.

Banco Central de Reserva de El Salvador (BCR) (1990). Revista Trimestral. El Salvador.

Banco Central de Reserva de El Salvador (BCR) (2007). Revista Trimestral. El Salvador. Recuperado de:http://www.bcr.gob.sv/esp/index.php?option=com wrapper\&view=wrapper\&Itemid $=288$

Caballero, G. (2004). Instituciones e historia económica: enfoques y teorías institucionales. Revista de Economía Institucional. No. 10. Recuperado de: http://www.economiainstitucional. com/pdf/No10/gcaballero10.pdf

Equipo Maíz (2003). Programa desajuste estructural y sus impactos en El Salvador. San Salvador. Recuperado de: http://searchworks.stanford.edu/view/6208144

Equipo Maíz (2005). Historia de El Salvador. San Salvador.

Guzmán, K., y Salinas, J. (2008). El patrón de acumulación de capital en El Salvador, a partir de la implementación de los PAE y PEE durante el periodo 1989 - 2007. San Salvador, Universidad de El Salvador, tesis no publicada.

Hutt, O., Montesinos M., y Ochoa, M. (2000). El Impacto de los Programas de Ajuste Estructural y Estabilización Económica en El Salvador. El Salvador. Saprin. Recuperado de: http:// www.saprin.org/elsalvador/research/els cover index.html

Moreno, R. (2004). La globalización neoliberal en El Salvador Un análisis de sus impactos e implicaciones. Barcelona. Recuperado de: http://www.mon-3.org/pdf/elsalvador.pdf

North, D. (1993). Instituciones, Cambio Institucional y Desempeño Económico. México. Fondo de Cultura Económica. Recuperado de: http://www.pabloabitbol.com/(NEP) files/12.\%20 North\%20Instituciones, $\% 20$ Cambio\%20Institucional\%20y\%20Desempe\%C3\%B10\%20 Econ\%C3\%B3mico\%20parte\%20Primera.pdf

Pelupessy, W. (1995). Agrarian transformation and economic adjustment in El Salvador 1960 1990. Tilburg. Retrieved from: https://pure.uvt.nl/portal/files/1211487/3955672.pdf

Peñate, M. (1997). El Salvador del conflicto armado a la negociación. San Salvador.

Rosales, O. (1990). El debate sobre el ajuste estructural en América Latina. Santiago de Chile, CEPAL. 
Revista de Política Económica • EISSN: 2215-4167

Vol. 1 (1) • Julio-Diciembre, 2015: 1-17

Guzmán López

DOI: http://dx.doi.org/10.15359/peds.1-1.3

Salinas Ventura

URL: http://www.revistas.una.ac.cr/politicaeconomica

Segovia, A. (2002). Transformación estructural y reforma económica En El Salvador. Guatemala. F \& G Editores.

Villalona, C. (2002, Junio 4). La Dolarización en El Salvador. Rebelión. Recuperado de: http:// www.rebelion.org/hemeroteca/economia/casencion040602.htm

Villareal, R. (2009) La Nueva Economía Institucional de mercado y el Estado de Derecho. Recuperado de: http://biblio.juridicas.unam.mx/libros/1/95/9.pdf 
Revista de Política Económica • EISSN: 2215-4167

Vol. 1 (1) • Julio-Diciembre, 2015: 1-17

Guzmán López

DOI: http://dx.doi.org/10.15359/peds.1-1.3

Salinas Ventura

URL: http://www.revistas.una.ac.cr/politicaeconomica

Anexo 1 Línea del tiempo 1979-2008

(La parte superior indica cambios economicos/sociales y politicos y la inferior cambios que de gran

trascendencia en el ámbito institucional)
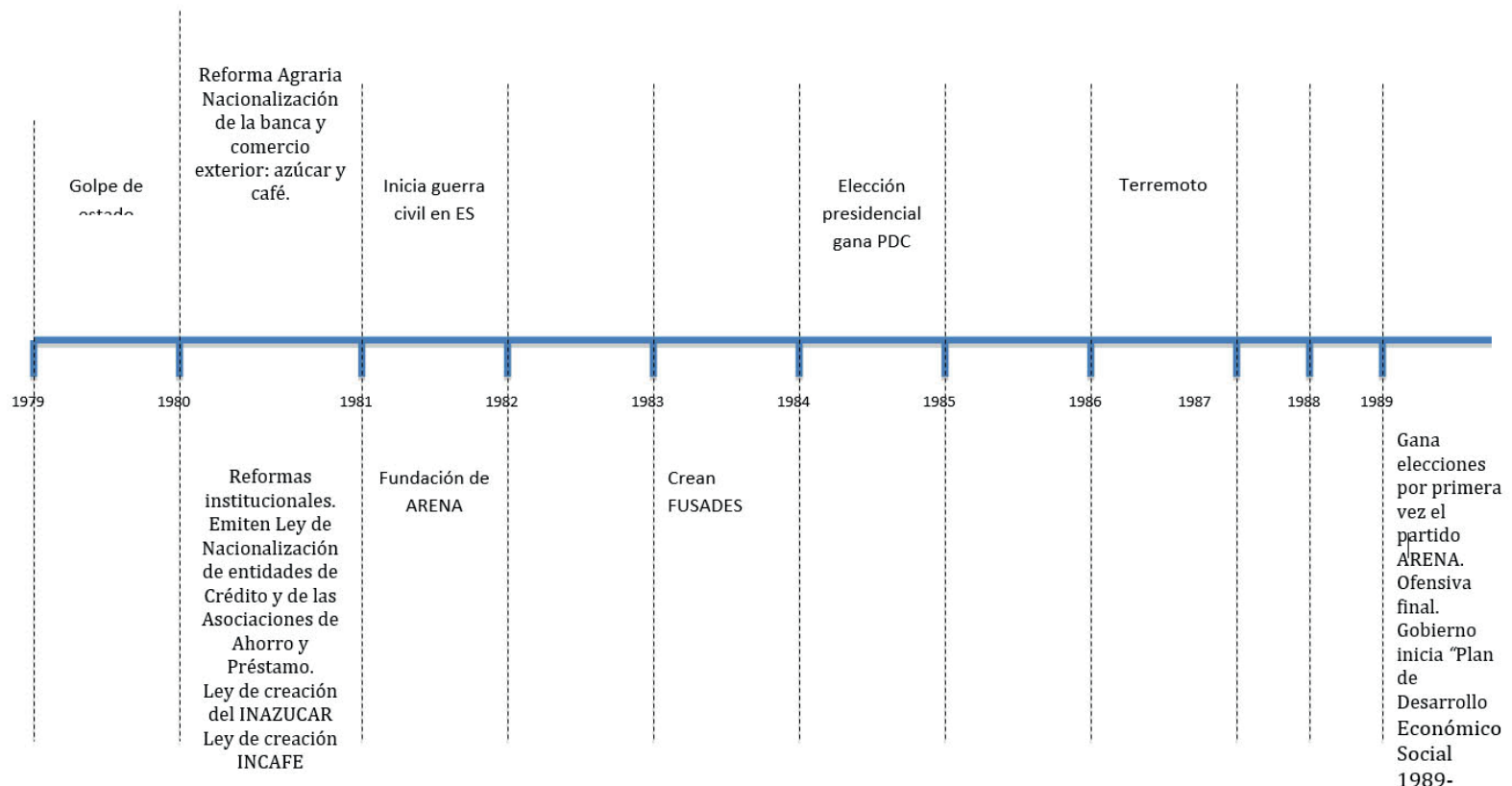

Gana

elecciones

por primera

vez el

partido

ARENA.

Ofensiva

final.

Gobierno

inicia "Plan

de

Desarrollo

Económico

Social

1989-

1994".

Se creó el

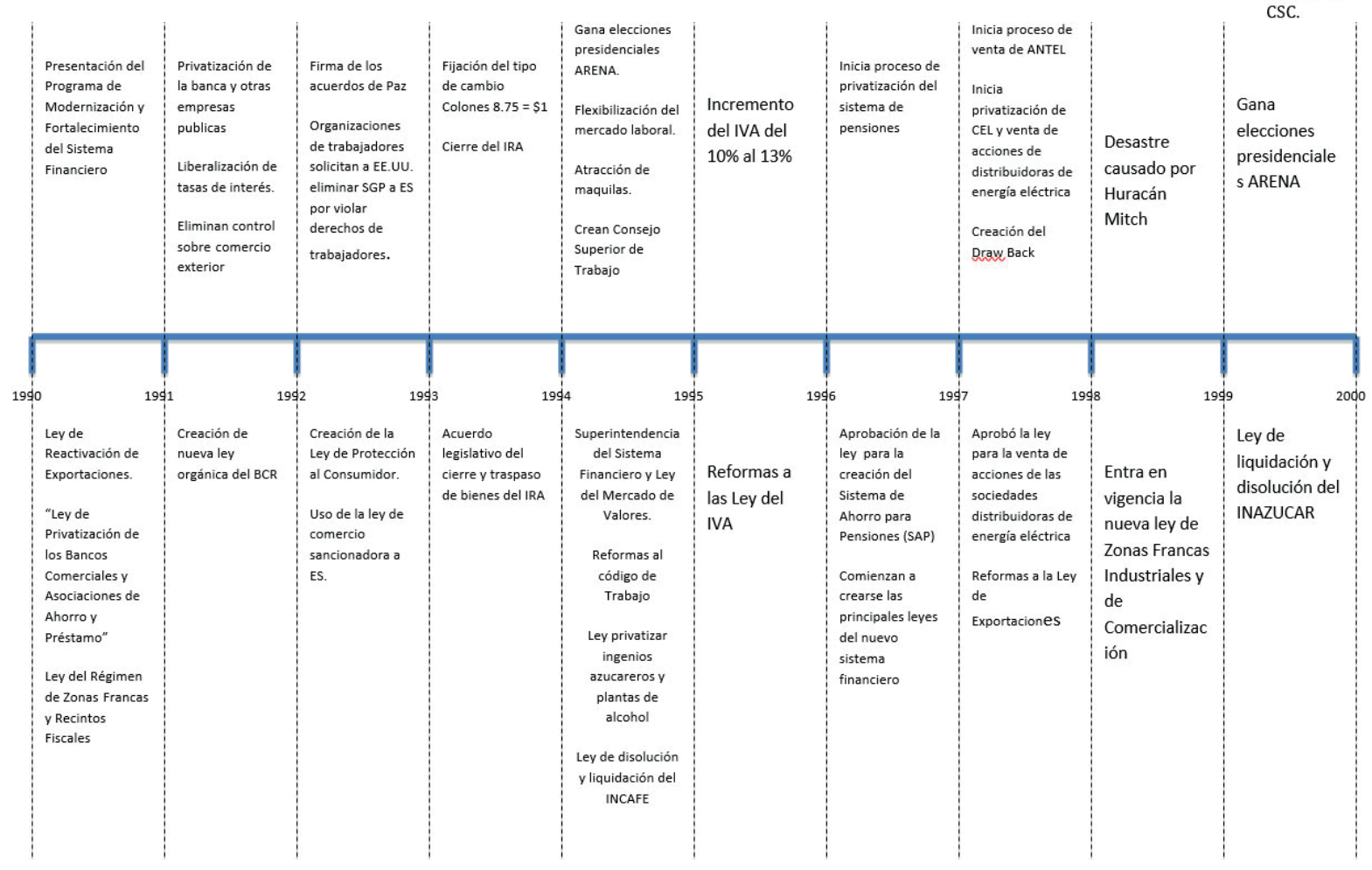


Revista de Política Económica • EISSN: 2215-4167

Vol. 1 (1) • Julio-Diciembre, 2015: 1-17

Guzmán López

DOI: http://dx.doi.org/10.15359/peds.1-1.3

Salinas Ventura

URL: http://www.revistas.una.ac.cr/politicaeconomica

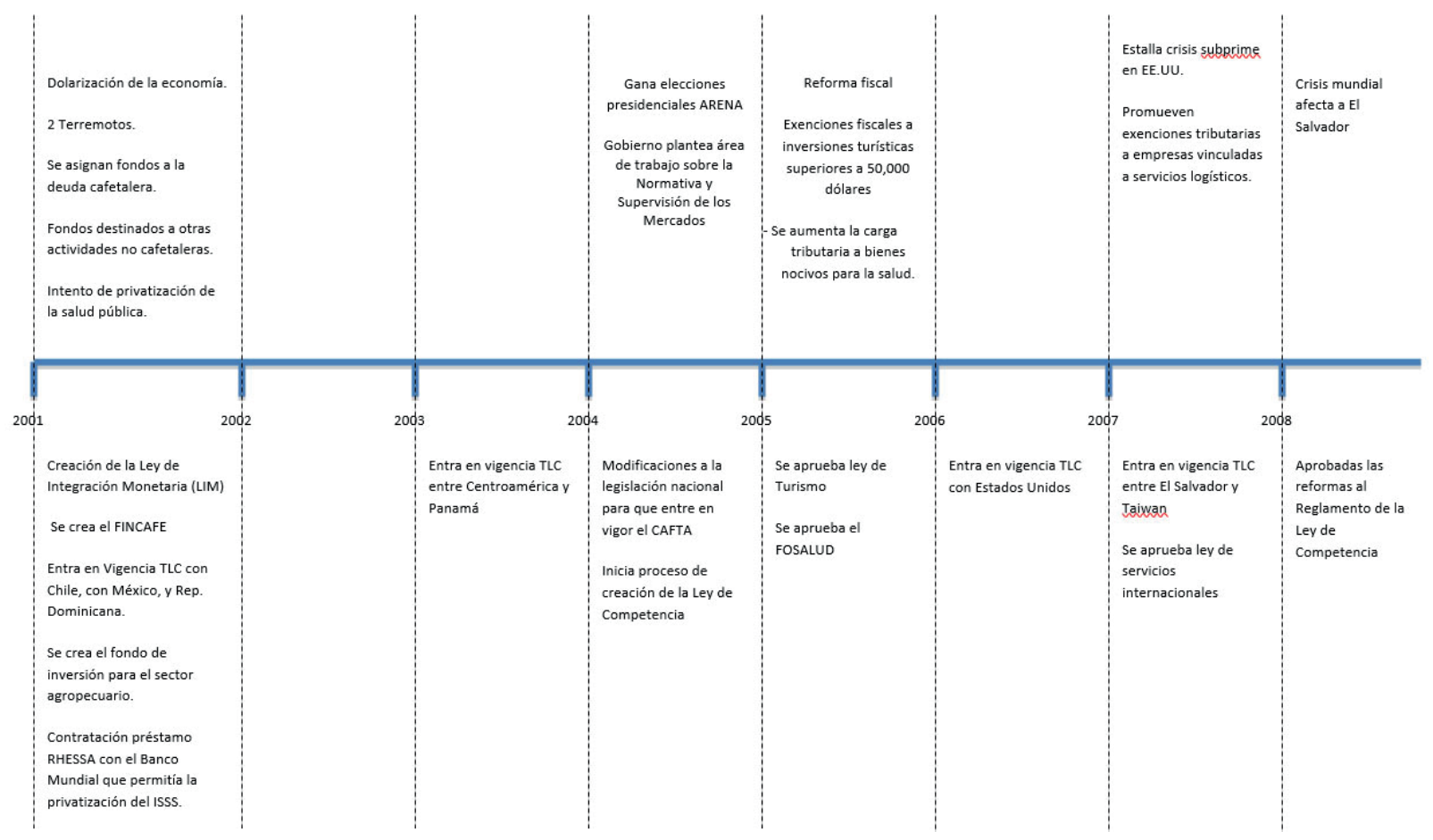

